\title{
Exploring trophic niches and parasite communities of sympatric Arctic charr and brown trout populations of southern Norway
}

\author{
Rachel A. Paterson (iD) Jelena Nefjodova $\cdot$ Romana K. Salis $\cdot$ Rune Knudsen
}

Received: 1 November 2018/Revised: 5 March 2019/Accepted: 1 April 2019/Published online: 9 May 2019

(C) The Author(s) 2019

\begin{abstract}
Catchment-scale variation between lake habitats has the potential to simultaneously influence the trophic niche and parasite community of fish hosts. In this study, we investigated the trophic niche and parasite community of sympatric Arctic charr and brown trout populations from two inter-connected southern Norwegian lakes at different altitudes. Arctic charr and brown trout occupied profundal and littoral habitats in each lake, respectively, whereas brown trout replaced Arctic charr in pelagic habitats of the
\end{abstract}

Guest editors: C. E. Adams, C. R. Bronte, M. J. Hansen, R. Knudsen \& M. Power / Charr Biology, Ecology and Management

Electronic supplementary material The online version of this article (https://doi.org/10.1007/s10750-019-3956-1) contains supplementary material, which is available to authorized users.

R. A. Paterson $(\square) \cdot$ J. Nefjodova

School of Biosciences, Cardiff University, Cardiff, Wales CF10 3AX, UK

e-mail: patersonr3@cardiff.ac.uk

R. K. Salis

Faculty of Biology, Aquatic Ecosystem Research, University Duisburg-Essen, Universitätsstr. 5, 45141 Essen, Germany

\section{R. Knudsen}

Department of Arctic and Marine Biology, UiT - The

Arctic University of Norway, Langnes, $\mathrm{Pb} 6050$,

9037 Troms $\emptyset$, Norway lower altitude lake. Distinct between-lake differences in diet and parasite community composition were noted for brown trout; however, both fish species showed highly overlapping trophically transmitted parasite communities regardless of the habitats each species used. Our results suggest that environmental differences over relatively limited geographical distances have the potential to influence fish habitat use and parasite community structure.

Keywords Salvelinus alpinus - Salmo trutta . Species richness - Diet

\section{Introduction}

Environment-induced alterations to distribution patterns of co-evolved species have the potential to uncouple trophic interactions essential for maintaining freshwater ecosystem structure and function (Winder $\&$ Schindler, 2004). Whilst temperature-related shifts in freshwater fish distribution patterns associated with range expansion or constrictions of cold and coolwater species are recognised (Comte et al., 2013), interactions involving parasites are frequently overlooked, despite the significant role parasites play in aquatic food web complexity and topology (Amundsen et al., 2009). Moreover, environmental gradients capable of uncoupling trophic interactions may not be 
restricted to latitudinal scales, with local environmental variation at the catchment scale (e.g. $0.65^{\circ} \mathrm{C}$ temperature decrease per $100 \mathrm{~m}$ altitude increase; Oskar Landgren, Norwegian Meteorological Institute, pers. comm.) also having the potential to simultaneously influence both the trophic niche and parasite assemblages of fish communities.

Sympatric Arctic charr (Salvelinus alpinus (L.)) and brown trout (Salmo trutta L.) populations in Norwegian lakes provide ideal study systems to assess local variability in trophic niche and parasite assemblages. Arctic charr have high phenotypic plasticity, capable of exploiting foraging resources from littoral, pelagic and profundal lake habitats (Klemetsen et al., 2003a). However, when in sympatry with brown trout, interspecific resource competition often results in the exclusion of Arctic charr from littoral habitats (e.g. Nilsson, 1963; Eloranta et al., 2013). Increasing water temperature and reduced dissolved oxygen in lake surface waters associated with climate change and anthropogenic stressors may further promote the constriction of exploitable habitat for the cold-water specialist Arctic charr (e.g. Elliott \& Elliott, 2010; Jeppesen et al., 2012). In contrast, the higher temperature tolerance of brown trout (Elliott \& Elliott, 2010) may to some extent facilitate the range expansion of this cool-water fish species into lake habitat niches made vacant by rising water temperatures.

Within-lake habitat shifts are likely to simultaneously result in parasite burden shifts, through both changes in diet (trophically transmitted parasites) and contact with free-living parasitic stages (e.g. trematode cercariae released from littoral dwelling snails). Examples from sympatric brown trout and Arctic charr populations show that brown trout parasite assemblages are dominated by taxa which utilise insect larvae and benthic crustacean prey from littoral habitats as intermediate hosts (e.g. Crepidostomum spp., Knudsen et al., 2008; Kristmundsson \& Richter, 2009). In contrast, pelagic Arctic charr are infected with parasite taxa associated with zooplankton prey (e.g. cestodes Dibothriocephalus spp., Proteocephalus sp. and Eubothrium salvelini (Schrank)), whereas parasites of profundal Arctic charr tend to be those associated with soft bottom benthic invertebrate prey, which are considered to be parasite species-poor hosts (Skoglund et al., 2013; Knudsen et al., 2016; Siwertsson et al., 2016). Brown trout may also acquire cestode infections via piscivory (e.g.
Dibothriocephalus spp. and Eubothrium crassum (Bloch); Curtis, 1984; Williams \& Jones, 1994). Such trophically transmitted parasites are acquired throughout the active foraging period for these salmonid hosts (Knudsen, 1995), and whilst diet analysis provides only a "snapshot" of the trophic niche, several studies have demonstrated that parasite community assemblages reveal the trophic niche of their hosts akin to other time-integrated measures (e.g. stable isotopes; Knudsen et al., 2014).

Currently, there is a plethora of studies from northern Norwegian lakes investigating parasite community structure across fish assemblages (e.g. Kennedy, 1977; Knudsen, 1995; Knudsen et al., 2008; Siwertsson et al., 2016; Kuhn et al., 2016b; Mocchetti et al., this volume). However, in southern Norway, where anthropogenic impacts to freshwater habitats may be most pronounced (e.g. increasing water temperature, invasive species introduction, agricultural runoff; Rask et al., 2000), research to date has focussed on single parasite-host/s associations (e.g. Vik, 1963; Halvorsen, 1970). In this study, we investigated the relationship between resource use and parasite assemblages of sympatric of Arctic charr and brown trout populations in two inter-connected lakes in southern Norway. We hypothesise that in the absence of local environmental differences, we would observe no difference in habitat use, diet or parasite community of each fish species between lakes. Specifically, we would predict to find Arctic charr occupying pelagic and profundal lake habitats and feeding predominantly on zooplankton prey, with brown trout occupying littoral habitats and feeding on benthos prey. We also hypothesise that parasite diversity and abundance would be higher in Arctic charr than sympatric brown trout (Knudsen et al., 2008), and that parasite abundance would be greater in the lower altitude lake (Paterson et al., 2018).

\section{Materials and methods}

Study lakes

Sympatric Arctic charr and brown trout populations were sampled in August 2017 from two lakes of the Skjenaldelva catchment, southern Trøndelag, Norway; Våvatnet $\left(63^{\circ} 19^{\prime} \mathrm{N}, 09^{\circ} 32^{\prime} \mathrm{E} ; 425\right.$ ha; max. depth $70 \mathrm{~m}, 300 \mathrm{~m} . a . s .1$.$) and Gangåsvatnet \left(63^{\circ} 16^{\prime} \mathrm{N}\right.$, 
$09^{\circ} 38^{\prime} \mathrm{E} ; 549$ ha, max. depth $33 \mathrm{~m}, 153$ m.a.s.l.). The lakes are connected via rivers Sagelva and Songa, and lake Songsjøen. There is a theoretical possibility for juvenile fish to migrate downstream, but not upstream due to the presence of a $6.7 \mathrm{~m}$ high hydropower dam at the outlet of Våvatnet. Both lakes are dimictic, oligotrophic and ice-free from May to December. Surrounding land use consists of pine and birch forest with some bogs. Small areas of modified agricultural land are present in the Gangåsvatnet catchment only. Water-temperature profiles were measured at $1 \mathrm{~m}$ intervals at each lake during fish sampling using a handheld YSI Professional Plus meter (YSI Inc., Yellow Springs, OH, U.S.A.). Late August water temperatures were higher in Gangåsvatnet, with $14.5^{\circ} \mathrm{C}$ from 0 to $9 \mathrm{~m}$ depth, then gradually decreasing from $11.8^{\circ} \mathrm{C}$ at $10 \mathrm{~m}$ to $7.5^{\circ} \mathrm{C}$ at $20 \mathrm{~m}$. In Våvatnet, surface waters to $11 \mathrm{~m}$ deep were $13.0^{\circ} \mathrm{C}$, decreasing to $11.9^{\circ} \mathrm{C}$ at $12 \mathrm{~m}$ and $7.0^{\circ} \mathrm{C}$ at $20 \mathrm{~m}$. Standardised Secchi depth was $4.5 \mathrm{~m}$ and $6 \mathrm{~m}$ in Gangåsvatnet and Våvatnet, respectively. The Våvatnet fish community consists of Arctic charr and brown trout populations only, whereas three-spined stickleback (Gasterosteus aculeatus L.) are also present in Gangåsvatnet. Further details about the fish populations in Våvatnet are provided by Langeland et al. (1991) and L'Abee-Lund et al. (1993).

\section{Sample collection}

Arctic charr and brown trout were sampled in August 2017 using a series of multi-mesh panel gillnets (mesh size: $10-55 \mathrm{~mm}$, knot-to-knot, in 5-m panel) set overnight for two nights per lake in the littoral ( 0 $15 \mathrm{~m}$ depths), profundal ( $>20 \mathrm{~m}$ ) zones (benthic nets, $1.5 \mathrm{~m}$ high, $40 \mathrm{~m} \mathrm{long}$ ), and in the pelagic zone (floating nets, $6 \mathrm{~m}$ high, $40 \mathrm{~m}$ long). In each lake, nine gillnets were used in the littoral zone, eight in the profundal zone and four in the pelagic zone $(0-6 \mathrm{~m}$ depth). In Gangåsvatnet, two additional floating nets were also set in the 6-12 m depth zone. Gill-netted fish were euthanized following the strict codes of practice in force in Europe, and approval from Institutional Animal Care and Use Committee (IACUC) was not necessary. The length (fork length, $\mathrm{mm}$ ), weight ( $\mathrm{g}$ ) and morphotype (littoral-spawning omnivore-, profundal-spawning piscivore- or profundal-spawning benthivore-morphs of Arctic charr only; Skoglund et al., 2015) were obtained from each fish at time of capture. To characterise the parasite communities, we primarily selected fish with fork length of 200$250 \mathrm{~mm}$ to minimise the potential effects of host age on parasite acquisition (Poulin, 2000; Table 1). Fish age (years) was determined from surface readings of ethanol preserved whole otoliths (Kristoffersen \& Klemetsen, 1991). In brief, the number of annuli were counted from the lateral otolith surface observed in a glycerol-filled black well plate under 6-50 $\times$ magnification by two experienced otolith readers. The body condition of each fish was assessed using Fulton's condition factor (Ricker, 1975):

$K=\frac{100 \times \text { weight }(\mathrm{g})}{\text { length }(\mathrm{cm})^{3}}$

Parasite and diet examinations

External surfaces (e.g. fins, gill opercula) were macroscopically examined for the presence of ectoparasites (e.g. Argulus sp.). Eyes, alimentary tract, swim bladder and kidney were systematically screened using a dissection microscope for endoparasites, with all recovered parasites fixed in $96 \%$ ethanol after identification. Parasite identification was based on previously described species in Norwegian Arctic charr and brown trout populations (see Sterud, 1999; Moravec, 2004), with parasite infection expressed as prevalence (percentage of fish infected with particular parasite taxon) and abundance (number of individuals of a particular parasite taxon per host; sensu Bush et al., 1997). Larval Dibothriocephalus dendriticus (Nitzsch) and D. ditremus (Creplin) (formerly Diphyllobothrium dendriticum and D. ditremum; Waeschenbach et al., 2017) were identified to genus level only. Trematode metacercariae (Diplostomum spp., Tylodelphys sp., Apatemon sp.) present in the eye of each fish were estimated from the left eye only. Comparisons among Arctic charr and brown trout populations from multiple lakes in Norway where both eyes were examined indicate trematode metacercariae do not display a left-right infection bias in these host species (Paterson \& Blasco-Costa, unpublished), and thus, dissections of a single eye per fish provides a robust assessment of trematode metacercariae prevalence and abundance. In cases where metacercariae were absent in the left eye ( $n=3$, Våvatnet brown trout), the right eye was 


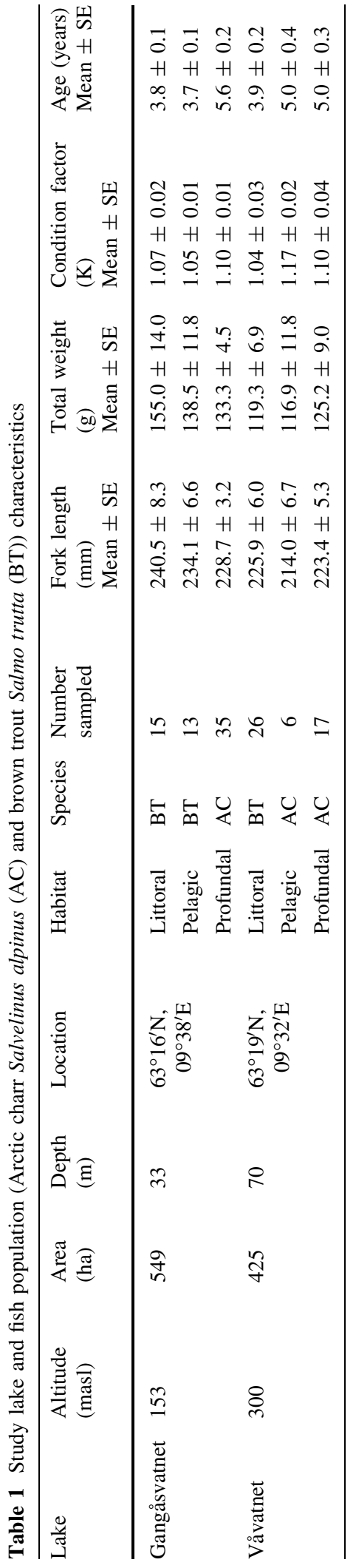

also examined to confirm the infection status. All dietary contents and parasites associated with the stomach were also fixed in $96 \%$ ethanol before identification to the lowest feasible taxonomic level ( $n=22$ prey taxa; see Eloranta et al., 2013 for more details). Prey were placed into four categories (iadult insects, ii-benthos [e.g. Eurycercus sp., chironomid and Ephemeroptera larvae], iii-zooplankton [e.g. Daphnia sp., Polyphemus sp., Bosmina sp.], ivfish), with their relative contribution to the diet expressed as a percentage of stomach fullness (Amundsen et al., 1996).

\section{Statistical analyses}

All statistical analyses were conducted in $\mathrm{R}$ version 3.4.2 (R Core Development Team, 2017). Normality and variance assumptions required for parametric tests were confirmed prior to analyses. In cases where normality and variance assumptions could not be met, we fitted appropriate model distributions. Analysis of variance was used to explore differences in body condition between fish species and lakes, whereas differences in fish age were assessed using a generalised linear model fitted with a Poisson distribution to account for over-dispersion. Differences in parasite taxon richness (number of parasite taxa per fish) and abundance (number of individual parasites per fish) between fish species and lakes were tested using separate general linear models and generalised linear models (quasipoisson distribution), respectively. Fish age was included as a variable in both latter models to account for the accumulation of parasites over time (Poulin, 2000). Only significant contrasts are presented in the results.

Canonical Correlation Analysis (vegan::CCorA version 2.4-5; Oksanen et al., 2017) was used to explore correlations between individual diet and parasite community composition between fish species, lakes and habitats. Abundance of trophically transmitted parasites and percentage prey volume for each individual fish were log- and chord-transformed, respectively, prior to analysis. 


\section{Results}

Fish community

A total of 423 fish were sampled from lakes Gangåsvatnet and Våvatnet, with Arctic charr and brown trout displaying contrasting habitat use between lakes. In Våvatnet, Arctic charr were the dominant species in the pelagic $(87.5 \%, n=64 ; 0-6 \mathrm{~m})$ and profundal $(100 \%, n=35)$ habitats, with brown trout dominating the littoral habitats $(97.5 \%, n=120)$. In contrast, brown trout dominated both littoral (98.4\%, $n=125)$ and pelagic $(96.8 \%, n=31 ; 0-12 \mathrm{~m})$ habitats in Gangåsvatnet, with Arctic charr dominating the profundal habitats $(95.8 \%, n=48)$. Sampled Arctic charr for parasite studies $(n=58$, Table 1$)$ were on average one to two years older than brown trout ( $n=54)$ from the same lake $(z=23.99, P<0.001)$ and in better body condition $\left(F_{1,110}=9.57\right.$, $P=0.003$; Table 1). Morphology characteristics indicated all Arctic charr belonged to the littoral-spawning omnivore morph.

\section{Diet}

Zooplankton, specifically Daphnia sp. and Polyphemus sp., was the dominant prey group for Arctic charr populations in both lakes regardless of habitat use (84.7-96.8\% stomach fullness; Table S1). Benthos (e.g. Eurycercus sp., chironomid larvae) abundance was higher in Arctic charr from Våvatnet than in Gangåsvatnet. Zooplankton was also the dominant prey for brown trout captured in littoral and pelagic habitats of Gangåsvatnet, though benthos and adult insects were major components of the diet of brown trout in the littoral habitats of both lakes. Fish were largely absent from the stomach contents of Arctic charr and brown trout from the study lakes, with the exception of Arctic charr from the profundal habitat of Gangåsvatnet, where 3-5 three-spined sticklebacks were present in the stomach contents of three charr (80-100\% fullness).

\section{Parasite community composition}

Ten parasite taxa were identified from Arctic charr and seven taxa from brown trout in the study lakes, of which six and four taxa were trophically transmitted to their respective fish host (Table 2). With the exception of the trematode Diplostomum sp., which are transmitted to fish via free-living larvae, the trophically transmitted adult trematode Phyllodistomum umblae (Fabricius) and larval cestode Dibothriocephalus spp. were the most common parasite taxa in both fish hosts. Adult cestodes E. salvelini and Proteocephalus sp. were also frequently observed in Arctic charr, and $E$. crassum in brown trout. Parasite taxon richness was the highest in Arctic charr, and did not differ overall between lakes, whereas brown trout acquired fewer parasites in Våvatnet than Gangåsvatnet (Fig. 1, Table 2; GLM LAKE:FISH $_{1,106}=7.612, \quad P=0.007$, Tukey HSD post hoc $P<0.001)$. Total parasite abundance was greater in Arctic charr than brown trout (Fig. 1; $\mathrm{GLM}_{\mathrm{FISH}}$ : $F_{1,103}=67.34, P<0.001$ ), with no observed interaction between fish species and lakes. Neither parasite taxon richness nor abundance was influenced by host age.

The diet of each individual fish significantly described the community of trophically transmitted parasites (Canonical Correlation adjusted $R^{2}=0.27$, $P<0.001$ ), and revealed distinct groups of overlapping resource use and parasite acquisition (Fig. 2). Canonical correlation axis 1 strongly opposed individual charr and trout that consumed zooplankton from those individuals consuming benthos and adult insects, resulting in both the separation of Våvatnet brown trout from Arctic charr, and the high overlap in resource use of Arctic charr populations regardless of lake or habitat. Canonical correlation axis 1 also opposed the cestode species Proteocephalus sp., Dibothriocephalus spp. and E. salvelini from trematode Crepidostomum spp., mirroring the separation in the fish populations observed from the diet composition. Canonical correlation axis 2 opposed E. crassum from all other parasite taxa, revealing the overlapping niche of Gangåsvatnet brown trout from both littoral and pelagic habitats which is distinct from all other fish populations.

\section{Discussion}

In general, Arctic charr and brown trout demonstrated distinct trophic niches and parasite communities in the two inter-connected study lakes. Arctic charr exhibited a zooplanktivorous diet and utilised almost exclusively off-shore habitats, in comparison to brown trout which dominated the littoral habitats of both 


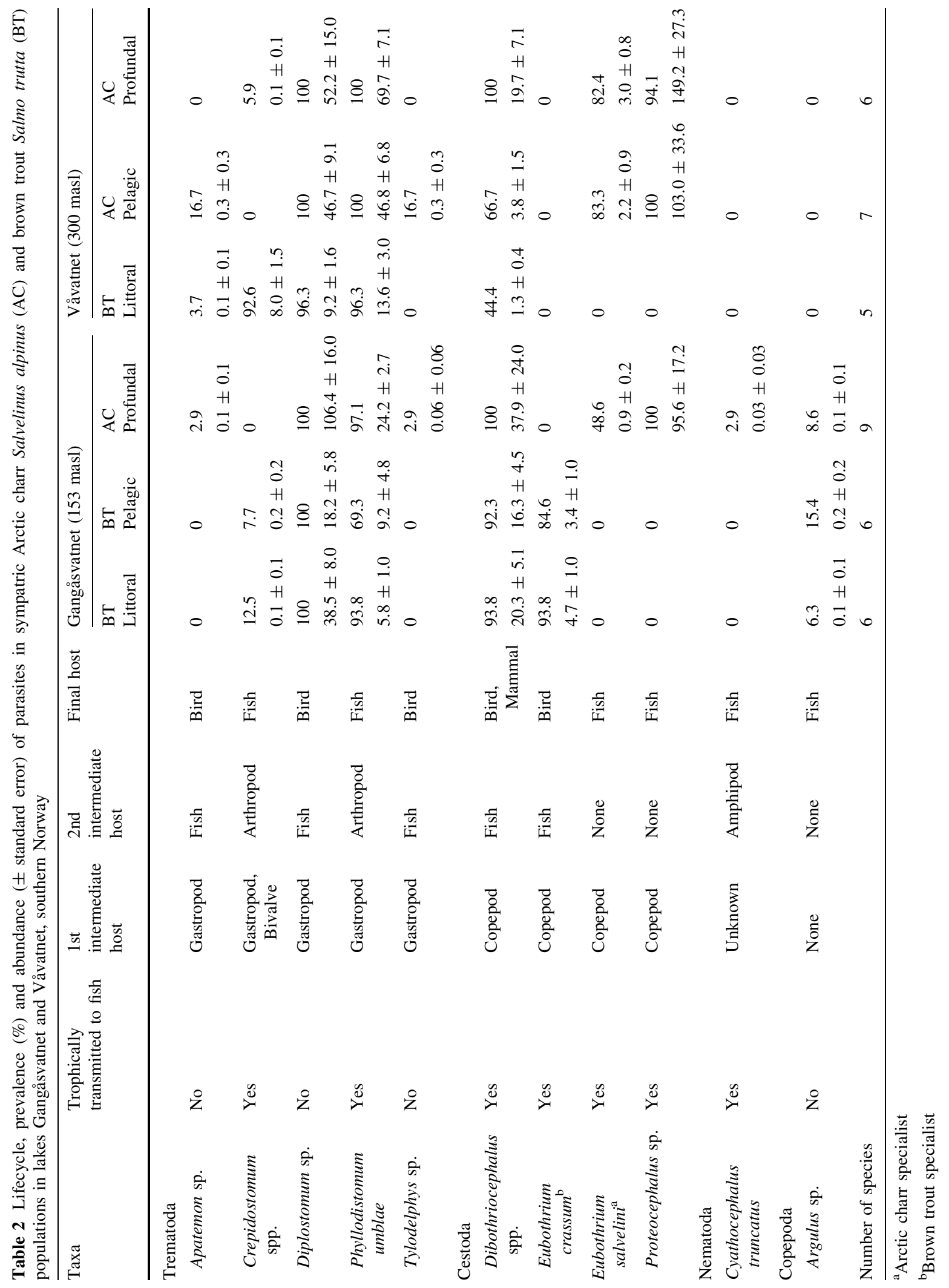




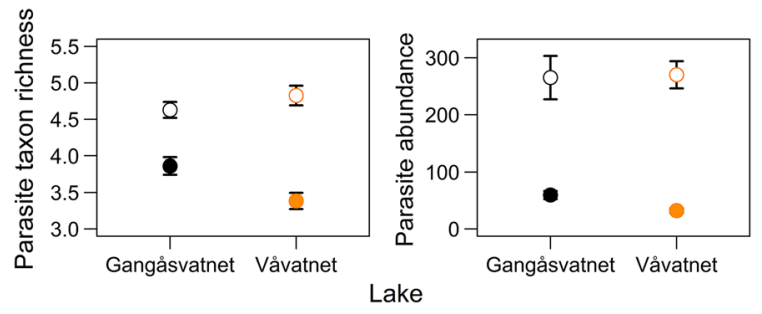

Fig. 1 Differences in parasite taxon richness (number of parasite species per fish; mean \pm standard error) and total parasite abundance (number of individual parasites per fish; mean \pm standard error) between sympatric populations of Arctic charr Salvelinus alpinus and brown trout Salmo trutta in lakes Gangåsvatnet and Våvatnet, southern Norway. Note symbols: lake: black—Gangåsvatnet, orange-Våvatnet; fish species: filled-S. trutta, open-S. alpinus

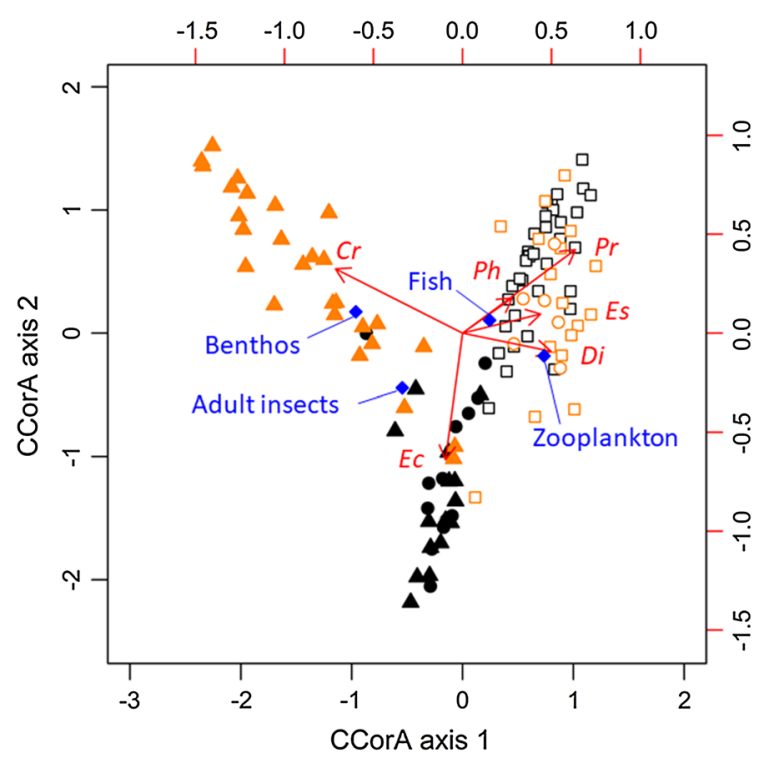

Fig. 2 Relationship between host diet (stomach contents; blue dots) and the trophically transmitted parasite community (red) of sympatric Arctic charr Salvelinus alpinus and brown trout Salmo trutta populations in two southern Norwegian lakes. Note - symbols; lake: black—Gangåsvatnet, orange-Våvatnet; fish species: filled-S. trutta, open-S. alpinus; habitat: trianglelittoral, circle-pelagic, square-profundal; parasite taxon codes: $\mathrm{Cr}$-Crepidostomum spp., $\mathrm{Ph}$-Phyllodistomum umblae, Di-Dibothriocephalus spp., Ec-Eubothrium crassum, Es-E. salvelini, $P r$-Proteocephalus sp. Canonical Correlation adjusted $R^{2}=0.27, P<0.001$

lakes. Parasite taxon richness was greater in Arctic charr than brown trout, as predicted by the greater diet breadth and thus potential encounter with parasite intermediate hosts, with parasite abundance in both fish species generally higher in the lower altitude lake
(Gangåsvatnet). Parasite community composition in brown trout from Gangåsvatnet littoral and pelagic habitats was similar, suggesting that although brown trout may move freely between the two habitats, there was still a reliance on prey sources from littoral habitats. Likewise, the parasite community of Arctic charr from both pelagic and profundal habitats in Våvatnet where characterised as taxa trophically transmitted from zooplankton rather than benthos.

Previous studies in Våvatnet (Langeland et al., 1991; L'Abée-Lund et al., 1993) and other southern Norwegian lakes (Sandlund et al., 2016; Jensen et al., 2017) have typically shown Arctic charr to be pelagic zooplanktivores. In contrast, zooplanktivorous Arctic charr in Gangåsvatnet were only caught in profundal habitats $(>20 \mathrm{~m})$, suggesting a degree of daily vertical migration may be occurring to facilitate the observed diet and parasite community. Seasonal vertical migration has been previously observed in Arctic charr, with populations from northern Norwegian lakes known to migrate to upper-open water and littoral habitats during winter (Klemetsen et al., 2003b), whereas populations from southern Norway are often relegated to the profundal habitats during the summer-stratification period (e.g. Jensen et al., 2017), largely due to their preference of water temperatures less than $12^{\circ} \mathrm{C}$ (Larsson et al., 2005; Siikavuopio et al., 2014). The apparent absence of Arctic charr from pelagic waters of Gangåsvatnet may also be a direct consequence of interactive competition with brown trout, who were also partly zooplanktivorous in the pelagic zone of this lake. Brown trout are typically a benthivore when in sympatry with Arctic charr (e.g. Nilsson, 1963; Klemetsen et al., 2003a, b; Eloranta et al., 2013); however, in a few instances brown trout have been documented to exhibit zooplanktivorous foraging strategies (Klemetsen, 1967; Piggott et al., 2018). Whilst both the habitat and dietary choice observed in this study can be considered "normal" for Arctic charr populations, the presence of zooplanktivore pelagic brown trout was unexpected.

Typically, parasite communities of zooplanktivorous Arctic charr are dominated by copepod transmitted parasites (Knudsen et al., 2008, 2011), as seen in both Våvatnet and Gangåsvatnet Arctic charr populations. However, parasite communities of northern Arctic charr populations are also characterised by parasite species transmitted from benthic prey (Frandsen et al., 1989; Due \& Curtis, 1995; Knudsen, 1995), largely attributed 
to the greater importance of benthos in their diet in this region (e.g. Knudsen et al., 2010). Furthermore, the overall Arctic charr-parasite taxon richness in the southern Norway study lakes was lower than previously observed in northern Norwegian lakes, due to the absence of a number of trophically- (e.g. nematode Philonema oncorhynchi from copepods, Cystidicola farionis from amphipods) and directly transmitted taxa (e.g. Salmincola edwardsii; Siwertsson et al., 2016; Paterson et al., 2018). In contrast, brown trout parasite communities in Våvatnet and Gangåsvatnet showed greater similarity to those of northern Norwegian brown trout populations (Hartvigsen \& Kennedy, 1993; Knudsen et al., 2008; Kristmundsson \& Richter, 2009). Although the zooplanktivorous brown trout in Gangåsvatnet were also infected with copepod-transmitted cestodes Dibothriocephalus spp. and E. crassum, the presence of these parasites may be linked to their predation on paratenic sticklebacks hosts (Curtis, 1984; Williams \& Jones, 1994; Kuhn et al., 2016a).

Whilst diet analysis may only represent a snapshot of the diet breadth of each fish, parasites act as longterm tracers of trophic niche (e.g. MacKenzie \& Abaunza, 1998). Thus, there is a general consistency among diet, habitat use and the parasite assemblages of fish hosts, as demonstrated by the correlation between the benthos prey-dominated diet of Våvatnet brown trout and Crepidostomum spp. infections, for example. In northern Norway, trophic segregation based on trophically transmitted parasites has been observed between sympatric populations of Arctic charr and brown trout in comparative lakes (Knudsen et al., 2008) and inter-individual Arctic charr with different feeding strategies (Knudsen et al., 2010, 2011). However, trophically transmitted parasites have also been shown to reflect consistent differences in trophic niches of polymorphic Arctic charr populations amongst lakes (Siwertsson et al., 2016; Mochetti et al., this volume).

The current study suggests environmental differences over relatively localised spatial scales, in terms of both distance $(<8 \mathrm{~km})$ and altitude $(150 \mathrm{~m})$, have the potential to influence the structure of the trophic niche and parasite community of sympatric fish species. Whilst similar patterns are also seen in Arctic charr populations from inter-connected lakes in northern Norway (e.g. 3-105 elevation and 6-8 km distance between lakes; Paterson et al., 2018), the current study demonstrates southern brown trout populations may also display localised differences in parasite assemblages and diet between lakes. Although previous studies have suggested habitat choice and diet of southern Arctic charr populations may be constrained (e.g. Gregersen et al., 2006; Sandlund et al., 2016; Jensen et al., 2017), our two lake comparison limits our ability to determine whether the observed differences between lakes are related to climatic differences associated with altitude from other factors known to shape fish-parasite assemblages elsewhere (e.g. lake productivity, area; Kennedy, 1978; Finstad et al., 2011). Whilst there is some evidence that Arctic charr populations in low latitude lakes may have lower parasite diversity than their high latitude counterparts (Dorucu et al., 1995; Due \& Curtis, 1995; Frandsen et al., 1989; Siwertsson et al., 2016), further studies are required across both altitudinal and latitudinal gradients of sympatric Arctic charr and brown trout populations, especially at lower latitudes, to determine the extent to which also local climate-induced gradients may be responsible for shifting the diet niche and parasite communities.

Acknowledgements We are grateful to the following people for their support: Halvard Kjønli (Gangåsvatnet Fiskelag) and Bjørn Sigmund Knudsen-fish sampling; extended Knudsen family_accommodation and transport; Kari and John Øystein Gjønnes (Hafella gård) - field laboratory; Alice Jones, Laina Dalsbø, Cesilie Lien, Karin Strand Johannessen-lab assistance; and Anna Siwertsson-statistical analysis. This study was funded by the UiT-The Arctic University of Norway, European Union's Horizon 2020 Research and Innovation Programme under the Marie Skłodowska-Curie Grant agreement (No. 663830; R. Paterson) and Cardiff Undergraduate Research Opportunities Programme, Cardiff University (J. Nefjodova). Further we thank three anonymous reviewers who provided comments that greatly improved the manuscript.

Open Access This article is distributed under the terms of the Creative Commons Attribution 4.0 International License (http:// creativecommons.org/licenses/by/4.0/), which permits unrestricted use, distribution, and reproduction in any medium, provided you give appropriate credit to the original author(s) and the source, provide a link to the Creative Commons license, and indicate if changes were made.

\section{References}

Amundsen, P.-A., H. M. Gabler \& F. J. Staldvik, 1996. A new approach to graphical analysis of feeding strategy from 
stomach contents data-modification of the Costello (1990) method. Journal of Fish Biology 48: 607-614.

Amundsen, P.-A., K. D. Lafferty, R. Knudsen, R. Primicerio, A. Klemetsen \& A. M. Kuris, 2009. Food web topology and parasites in the pelagic zone of a subarctic lake. Journal of Animal Ecology 78: 563-572.

Bush, A. O., K. D. Lafferty, J. M. Lotz, A. W. Shostak, et al., 1997. Parasitology meets ecology on its own terms: Margolis et al. revisted. Journal of Parasitology 83: 575-583.

Curtis, M. A., 1984. Diphyllobothrium spp. and the Arctic charr: parasite acquisition and its effects on a lake-resident population. In Johnson, L. \& B. I. Burns (eds.), Biology of the Arctic charr. University of Manitoba Press, Winnipeg: 395-411.

Comte, L., L. Buisson, M. Daufresne \& G. Grenouillet, 2013. Climate-induced changes in the distribution of freshwater fish: observed and predicted trends. Freshwater Biology 58: 625-639.

Dorucu, M., C. E. Adams, F. A. Huntingford \& D. W. T. Crompton, 1995. How fish-helminth associations arise: an example from Arctic charr in Loch Rannoch. Journal of Fish Biology 47: 1038-1043.

Due, T. T. \& M. A. Curtis, 1995. Parasites of freshwater resident and anadromous Arctic charr (Salvelinus alpinus) in Greenland. Journal of Fish Biology 46: 578-592.

Elliott, J. M. \& J. A. Elliott, 2010. Temperature requirements of Atlantic salmon Salmo salar, brown trout Salmo trutta and Arctic charr Salvelinus alpinus: predicting the effects of climate change. Journal of Fish Biology 77: 1793-1817.

Eloranta, A., R. Knudsen \& P.-A. Amundsen, 2013. Niche segregation of coexisting Arctic charr (Salvelinus alpinus) and brown trout (Salmo trutta) constrains food web coupling in subarctic lakes. Freshwater Biology 58: 207-221.

Finstad, A. G., T. Forseth, B. Jonsson, E. Bellier, T. Hesthagen, A. J. Jensen, D. O. Hessen \& A. Foldvik, 2011. Competitive exclusion along climate gradients: energy efficiency influences the distribution of two salmonid fishes. Global Change Biology 17: 1703-1711.

Frandsen, F., H. J. Malmquist \& S. S. Snorrason, 1989. Ecological parasitology of polymorphic Arctic charr, Salvelinus alpinus (L.), in Lake Thingvallavatn, Iceland. Journal of Fish Biology 34: 281-297.

Gregersen, F., P. Aass, L. A. Vøllestad \& J. H. L’Abée-Lund, 2006. Long-term variation in diet of Arctic char, Salvelinus alpinus, and brown trout, Salmo trutta: effects of changes in fish density and food availability. Fisheries Management and Ecology 13: 243-250.

Halvorsen, O., 1970. Studies of the helminth fauna of Norway $\mathrm{XV}$ : on the taxonomy and biology of plerocercoids of $\mathrm{Di}$ phyllobothrium Cobbold, 1858 (Cestoda, Pseudophyllidea) from north-western Europe. Nytt Magasin for Zoologi 18: 113-174.

Hartvigsen, R. \& C. R. Kennedy, 1993. Patterns in the compositions and richness of helminth communities in brown trout, Salmo trutta, in a group of reservoirs. Journal of Fish Biology 43: 603-615.

Jensen, H., M. Kiljunen, R. Knudsen \& P.-A. Amundsen, 2017. Resource partitioning in food, space and time between Arctic charr (Salvelinus alpinus), brown trout (Salmo trutta) and European whitefish (Coregonus lavaretus) at the southern edge of their continuous coexistence. PLoS ONE 12: e0170582.

Jeppesen, E., T. Mehner, I.J. Winfield, K. Kangur, J. Sarvala, D. Gerdeaux, M. Rask, H.J. Malmquist, K. Holmgren, P. Volta, \& S. Romo, 2012. Impacts of climate warming on the long-term dynamics of key fish species in 24 European lakes. Hydrobiologia 694: 1-39.

Kennedy, C. R., 1977. Distribution and zoogeographical characteristics of the parasite fauna of char Salvelinus alpinus in Arctic Norway, including Spitsbergen and Jan Mayen islands. Astarte 10: 49-55.

Kennedy, C. R., 1978. An analysis of the metazoan parasitocoenoses of brown trout Salmo trutta from British Lakes. Journal of Fish Biology 13: 255-263.

Klemetsen, A., 1967. On the feeding habits of the population of brown trout (Salmo trutta L.) in Jølstervann, West Norway, with special reference to the utilization of planktonic crustaceans. Nytt Magasin for Zoology 15: 50-67.

Klemetsen, A., P.-A. Amundsen, B. Dempson, B. Jonsson, N. Jonsson, M. F. O'Connell \& E. Mortensen, 2003a. Atlantic salmon Salmo salar L., brown trout Salmo trutta L. and Arctic charr Salvelinus alpinus (L.): a review of aspects of their life histories. Ecology of Freshwater Fish 12: 1-59.

Klemetsen, A., R. Knudsen, F. Staldvik \& P.-A. Amundsen, 2003b. Habitat, diet and food assimilation of Arctic char Salvelinus alpinus under the winter in two subarctic lakes. Journal of Fish Biology 62: 1082-1098.

Knudsen, R., 1995. Relationships between habitat, prey selection and parasite infection in Arctic charr (Salvelinus alpinus). Nordic Journal of Freshwater Research 71: 333-344.

Knudsen, R., P.-A. Amundsen, R. Nilsen, R. Kristoffersen \& A. Klemetsen, 2008. Food borne parasites as indicators of trophic segregation between Arctic charr and brown trout. Environmental Biology of Fishes 83: 107-116.

Knudsen, R., R. Primicerio, P.-A. Amundsen \& A. Klemetsen, 2010. Temporal stability of individual feeding specialization may promote speciation. Journal of Animal Ecology 79: 161-168.

Knudsen, R., A. Siwertsson, C. E. Adams, M. Garduño-Paz, J. Newton \& P.-A. Amundsen, 2011. Temporal stability of niche use exposes sympatric Arctic charr to alternative selection pressures. Evolutionary Ecology 25: 589-604.

Knudsen, R., A. Siwertsson, C. E. Adams, J. Newton \& P.-A. Amundsen, 2014. Similar patterns of individual niche use are revealed by different time-integrated trophic tracers (stable isotopes and parasites). Ecology of Freshwater Fish 23: 259-268.

Knudsen, R., P.-A. Amundsen, A. P. Eloranta, B. Hayden, A. Siwertsson \& A. Klemetsen, 2016. Parallel evolution of profundal Arctic charr morphs in two contrasting fish communities. Hydrobiologia 783: 239-248.

Kristmundsson, A. \& S. H. Richter, 2009. Parasites of resident Arctic charr, Salvelinus alpinus, and brown trout, Salmo trutta, in two lakes in Iceland. Iceland Agriculture Sciences 22: 5-18.

Kristoffersen, K. \& A. Klemetsen, 1991. Age determination of Arctic charr (Salvelinus alpinus) from surface and cross section of otoliths related to otolith growth. Nordic Journal of Freshwater Research 66: 98-107. 
Kuhn, J. A., A. Frainer, R. Kristoffersen, R. Knudsen \& P.-A. Amundsen, 2016a. Effects of fish species composition on Diphyllobothrium spp. infections in brown trout-is threespined stickleback a key species? Journal of Fish Diseases 39: 1313-1323.

Kuhn, J. A., R. Knudsen, R. Kristoffersen, R. Primicerio \& P.-A. Amundsen, 2016b. Temporal changes and between-host variation in the intestinal parasite community of Arctic charr in a subarctic lake. Hydrobiologia 783: 79-91.

L'Abée-Lund, J. H., A. Langeland, B. Jonsson \& O. Ugedal, 1993. Spatial segregation by age and size in Arctic charr: a trade-off between feeding possibility and risk of predation. Journal of Animal Ecology 62: 160-168.

Langeland, A., J. H. L'Abée-Lund, B. Jonsson \& N. Jonsson, 1991. Resource partitioning and niche shift in Arctic charr Salvelinus alpinus and brown trout Salmo trutta. Journal of Animal Ecology 60: 895-912.

Larsson, S., T. Forseth, I. Berglund, A. J. Jensen, I. Näslund, J. M. Elliott \& B. Jonsson, 2005. Thermal adaptation of Arctic charr: experimental studies of growth in eleven charr populations from Sweden, Norway and Britain. Freshwater Biology 50: 353-368.

MacKenzie, K. \& P. Abaunza, 1998. Parasites as biological tags for stock discrimination of marine fish: a guide to procedures and methods. Fisheries Research 38: 45-56.

Moravec, F., 2004. Metazoan parasites of salmonid fishes of Europe. Academia, Prague.

Nilsson, N.-A., 1963. Interactions between trout and char in Scandinavia. Transactions of the American Fisheries Society 92: 276-285.

Oksanen, J., F. G. Blanchet, M. Friendly, R. Kindt, P. Legendre, D. McGlinn, P. R. Minchin, R. B. O'Hara, G. L. Simpson, P. Solymos, M. H. H. Stevens, E. Szoecs \& H. Wagner, 2017. vegan: Community Ecology Package. Version 2.4-5. https://cran.r-project.org/web/packages/vegan/index.html.

Paterson, R. A., R. Knudsen, I. Blasco-Costa, A. M. Dunn, S. Hytterød \& H. Hansen, 2018. Determinants of parasite distribution in Arctic charr populations: catchment structure versus dispersal potential. Journal of Helminthology. https://doi.org/10.1017/s0022149x18000482.

Piggott, C. V., E. Verspoor, R. Greer, O. Hooker, J. Newton \& C. E. Adams, 2018. Phenotypic and resource use partitioning amongst sympatric, lacustrine brown trout, Salmo trutta. Biological Journal of the Linnean Society 124: 200-212.

Poulin, R., 2000. Variation in the intraspecific relationship between fish length and intensity of parasitic infection: biological and statistical causes. Journal of Fish Biology 56: $123-137$.

R Development Core Team., 2017. R: A Language and Environment for Statistical Computing. R Foundation for Statistical Computing, Vienna.
Rask, M., M. Appelberg, T. Hesthagen, J. Tammi \& A. Lappalainen, 2000. Fish status survey of Nordic lakes: species composition, distribution, effects of environmental changes. Nordic Council of Ministers, Copenhagen.

Ricker, W. E., 1975. Computation and interpretation of biological statistics of fish populations. Bulletin of the Fisheries Research Board of Canada 191: 1-382.

Sandlund, O. T., A. P. Eloranta, R. Borgstrøm, T. Hesthagen, S. I. Johnsen, J. Museth \& S. Rognerud, 2016. The trophic niche of Arctic charr in large southern Scandinavian lakes is determined by fish community and lake morphometry. Hydrobiologia 783: 117-130.

Siikavuopio, S. I., B.-S. Sæther, H. Johnsen, T. Evensen \& R. Knudsen, 2014. Temperature preference of juvenile Arctic charr originating from different thermal environments. Aquatic Ecology 48: 313-320.

Siwertsson, A., B. Refsnes, A. Frainer, P.-A. Amundsen \& R. Knudsen, 2016. Divergence and parallelism of parasite infections in Arctic charr morphs from deep and shallow lake habitats. Hydrobiologia 783: 131-143.

Skoglund, S., R. Knudsen \& P.-A. Amundsen, 2013. Selective predation on zooplankton by pelagic Arctic charr, Salvelinus alpinus, in six subarctic lakes. Journal of Ichtyology 53: 849-855.

Skoglund, S., A. Siwertsson, P.-A. Amundsen \& R. Knudsen, 2015. Morphological divergence between three Arctic charr morphs - the significance of the deep-water environment. Ecology and Evolution 5: 3114-3129.

Sterud, E. 1999. Parasitter hos norske ferskvannsfisk. Norsk Zoologisk Forening, Oslo. Rapport 7. (In Norwegian).

Vik, R., 1963. Studies of the helminth fauna of Norway. IV. Occurrence and distribution of Eubothrium crassum (Bloch, 1779) and E. salvelini (Schrank, 1790) (Cestoda) in Norway, with notes on their life cycles. Nytt Magasin for Zoologi 11: 47-73.

Waeschenbach, A., J. Brabec, T. Scholz, D. T. J. Littlewood \& R. Kuchta, 2017. The catholic taste of broad tapewormsmultiple routes to human infection. International Journal for Parasitology 47: 831-843.

Williams, H. H. \& A. Jones, 1994. Parasitic Worms of Fish. Taylor \& Frances Ltd., London.

Winder, M. \& D. E. Schindler, 2004. Climate change uncouples trophic interactions in an aquatic ecosystem. Ecology 85: 2100-2106.

Publisher's Note Springer Nature remains neutral with regard to jurisdictional claims in published maps and institutional affiliations. 